\title{
Squeezing a rainfall record out of desert sand dunes
}

\author{
Abi Stone ${ }^{1,2}$
}

\begin{abstract}
Pore moisture within desert sand dunes provides a novel archive for paleomoisture availability. Hydrostratigraphies are produced from variations in chemical tracers in a vertical profile. The applicability has been demonstrated in drylands in five continents and three examples are given here.
\end{abstract}

Reconstructing past rainfall fluctuations in drylands is challenging. The deposition of sedimentary archives, such as sand dunes, are mediated by a number of factors, of which changing moisture availability is just one. Former river courses, and former lakes fed by rivers, often record changes imported from a climatic zone outside their dryland location (exogenous systems). Speleothems are restricted to limestone terranes and tend to be discontinuous records in drylands. Isotopic records within hyrax middens have growing potential, but are also spatially restricted to areas with rock-ledge habitats. Therefore, developing further proxies capable of recording changes in moisture availability is extremely valuable for dryland Quaternary environmental reconstruction.

Chemical tracers within sand dune pore moisture offer a novel additional proxy for paleomoisture availability. When and where this moisture moves downward, fluctuations in its chemical signature with depth can be utilized to establish a record of changes to moisture availability through time, based on the transport of a signal built up in the near-surface zone (Fig. 1). The resolution and timescale of the preserved hydrostratigraphy depends on the rate of moisture movement and the thickness of sediment (Stone and Edmunds 2016). Applications over a range of timescales are briefly explored to demonstrate the utility of this approach.

\section{Basis of tracer technique}

Pore moisture in sand dunes above the water table is described as the unsaturated zone (USZ) of the hydro(geo)logical cycle. It is in this USZ that hydrostratigraphies can be reconstructed, based upon variations in chloride concentration in pore moisture. The chloride signal is established in the near-surface recycling zone, and this inherited signal is then transmitted vertically in the moisture that is infiltrating through the sediment, so that a depth-based profile of samples represents a temporal record (Fig. 1).

The input of moisture at the surface from precipitation contains solutes, including chloride. The long-term average concentration of this input can be established empirically, and varies between regions as a function of continentality. The chloride input gets modified in the near-surface zone by evapotranspiration, which removes water and enriches the chloride concentration, and by mixing (Fig. 1). Below the zone of recycling, moisture moves downwards, and movement is closest to homogenous in sand-rich sediments containing some finer-fraction sediment (e.g. Gehrels et al. 1998). This means that the concentrations of chloride in pore-moisture at sequential depths are a record of a climatically driven process in the zone of recycling before being transmitted down to that depth. The record can be read as low(high) chloride concentrations recording high(low) moisture availability. A certain degree of smoothing of the record will have occurred in the recycling zone, including smoothing variations between individual rainfall events.

\section{Records of land-use changes and precipitation}

USZ hydrostratigraphies can be used to quantify increases in moisture flux through sediments as a result of land-use change. In southwestern Australia, clearance of native eucalyptus vegetation increased recharge rates from $\sim 0.1 \mathrm{~mm} \mathrm{yr}^{-1}$ under intact vegetation to $2.5-8.5 \mathrm{~mm} \mathrm{yr}^{-1}$ and 3.8-28.0 $\mathrm{mm} \mathrm{yr}^{-1}$ under pasture and cereal cropped land respectively (Cook et al. 1994). This is demonstrated clearly in the hydrostratigraphy by a vertical displacement of a single subsurface chloride peak in cleared sites compared to intact sites.

The influence of artificial irrigation can also be investigated. In the Thar Desert, northwest India, multi-decadal length hydrostratigraphies demonstrate a recharge rate under irrigated cropland of 18-98 $\mathrm{mm} \mathrm{yr}^{-1}$ as compared to $2.7-5.6 \mathrm{~mm} \mathrm{yr}^{-1}$ in a non-irrigated dune (Scanlon et al. 2010).

Over timescales of a few hundred years, the potential of USZ hydrostratigraphies as proxies for precipitation has also been demonstrated. For example, a 108-year-long

\section{Moisture inputs, outputs and movement}

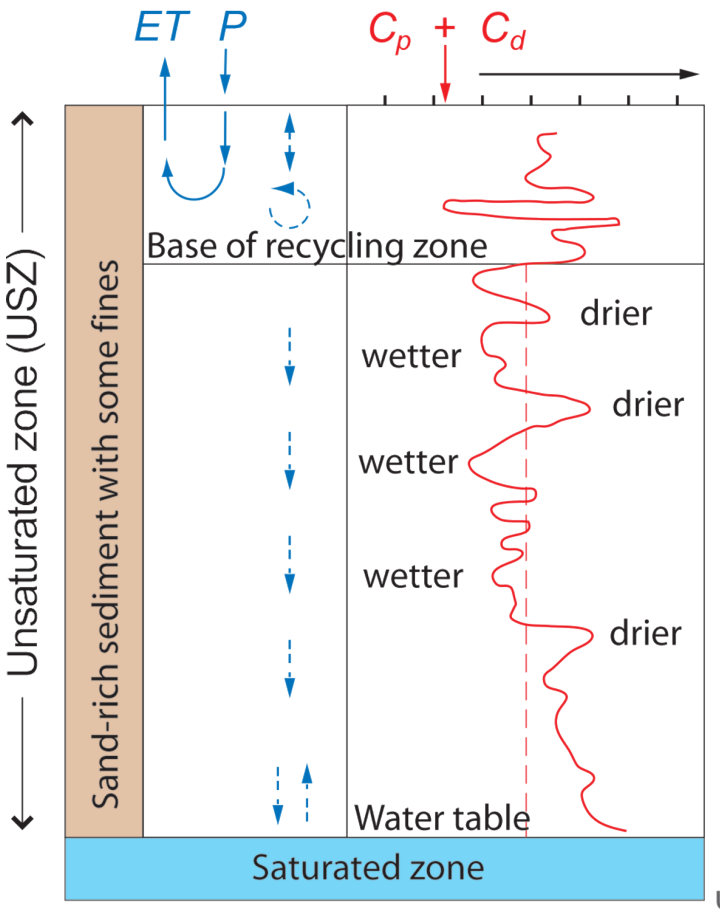

\section{Summary explanation}

Input of chloride tracer<smiles>C1C2CC3CC1C3C2</smiles>

Modifiation of chloride signature in recyling zone<smiles>C1C2CC1C1CC21</smiles>

Transmission of established signature through the USZ

- discrete samples with depth represent the

former moisture balance in the recycling zone deeper samples represent older episodes<smiles>C1C2CC1C2</smiles>

Moisture reaching the water table represents the upper age limit of the record

Figure 1: Schematic diagram to demonstrate the basis of the unsaturated zone hydrostratigraphy approach ( $P$ is precipitation, ET is evapotranspiration, $C_{p}$ is concentration of chloride in precipitation and $C_{d}$ is concentration of chloride in dry deposited material), modified from Stone and Edmunds (2016). 
hydrostratigraphy from Louga, Senegal correlates well with both a local precipitation record and Senegal River flow data, and records the 1970s Sahel drought and the 1940s dry period (Edmunds and Tyler 2002).

\section{Records of climatic change in central Asia} Arguably the most significant development for dryland Quaternary environmental reconstruction using this approach comes from the decadal-scale resolution, multi-millennial length hydrostratigraphies from mega-dunes within the Badain Jaran desert in China (e.g. Ma and Edmunds 2006; Gates et al. 2008; Ma et al. 2009). The longest is a $30 \mathrm{~m}$ record spanning 2050 years, with four others $>500$ years. Comparisons with independent paleohydrological proxies for northern China have been made, which highlight wetter intervals in this region around 1350-1400, 1550-1600 and 1750-1800 and after 1990 (Fig. 2A-D). The three earliest wetter intervals are supported by above-average values for precipitation reconstructed from Juniper tree-ring growth records from the northeast Qinghai Province (Sheppard et al. 2004) and the middle phases are also phases of above-average ice-core accumulation in the Guliya ice core (Thompson et al. 1997) and above-average wetness in the flood-drought index (based on historical documents) (Zhang and Crowley 1989). However, the overall correspondence is not perfect, with some larger incursions in the other proxies not appearing in the USZ hydrostratigraphies, suggesting some regional complexity in paleohydrology in this region.

\section{Reconstructing long-term dryland aridification}

Initially driven by a motivation to assess whether the deep USZ in the semi-arid western United States might safely store nuclear waste without contaminating groundwater, more than a dozen hydrostratigraphies record an aridity trend through the Late Glacial and into the Holocene (e.g. Scanlon 1991; Phillips 1994; Tyler et al. 1996). The majority of profiles place this shift at around 16,000 to 13,000 years ago. There is one $240 \mathrm{~m}$ thick hydrostratigraphy at the Nevada nuclear test core than contains an earlier cycle from higher recharge to greater aridity during Marine Oxygen Isotope Stage (MIS) 5 (Tyler et al. 1996).

\section{Conclusions and outlook}

The unsaturated zone (USZ) in dryland environments is a novel and valuable archive providing a direct paleomoisture proxy, where the enrichment of chloride acts as a tracer for the balance between precipitation and evapotranspiration. The sand-rich sediments required for this approach cover a portion of drylands where it is extremely challenging to reconstruct hydrological variations over the Quaternary, owing to poor preservation of biological material and a scarcity of water-lain sediments and speleothems.

Further development of modeling approaches that incorporate transient fluxes of water and tracer input concentrations (Ginn and Murphy 1997) will continue to reduce

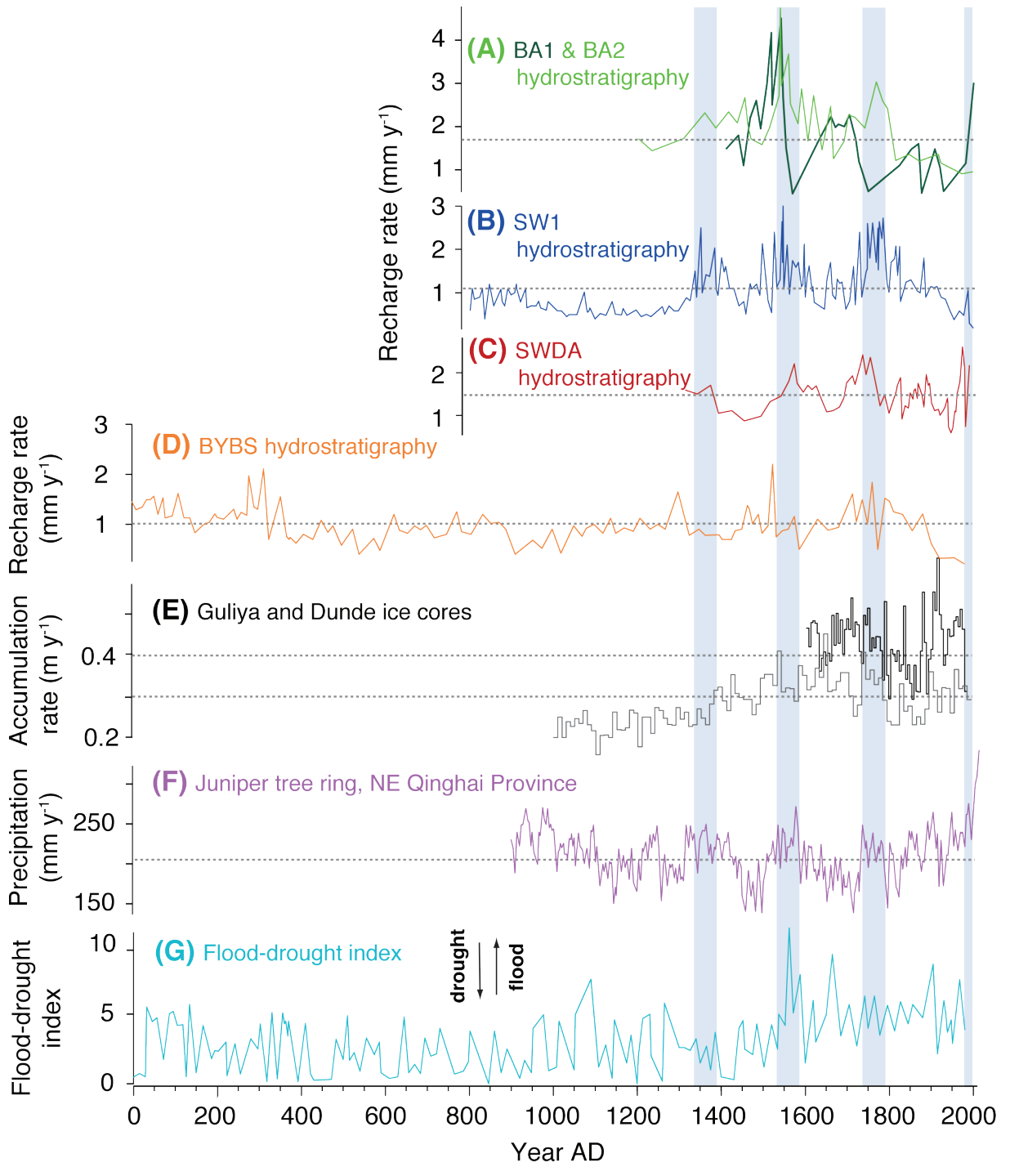

Figure 2: Paleohydrologic records from five USZ hydrostratigraphies from the Badain Jaran desert (A) BA1 (solid line) and BA2 (dashed line) near Baoritelegai (Ma and Edmunds 2006), (B) SW1 near Sayinwusu (Ma and Edmunds 2006), (C) SWDA near Lake Sayinwsus (Gates et al. 2008), (D) BYBS near Lake Bayan Bur (Ma et al. 2009) and (E) Dunde (black line) and Guliya (gray line) ice-core accumulation rate (Thompson et al. 1997), which are ca. $400 \mathrm{~km}$ and $2000 \mathrm{~km}$ from the Badain Jaran desert. (F) Juniper tree-ring growth record from the NE Qinghai Province, China (Sheppard et al. 2004), which is ca. $500 \mathrm{~km}$ south of the Badain Jaran desert. (G) drought-flood index for China from historical documents (Zhang and Crowley 1989), modified from Stone and Edmunds (2016). The blue shaded vertical lines highlight where at least two hydrostratigraphies and two or more of the supporting proxy archive record wetter than average conditions.

uncertainties within USZ hydrostratigraphies. Studies must routinely verify the suitability of the sediment texture at a site-by-site basis and avoid sediments that experience a very heterogeneous vertical flow of water.

USZ hydrostratigraphies have proven potential within drylands (Stone and Edmunds 2016). Depending on the thickness of the USZ sediment and the rate of moisture infiltration, hydrostratigraphies can record low-resolution trends in humidity-aridity over deglacial timescales, a decadal-resolution paleomoisture proxy for the last two millennia or quantify changes in moisture flux in sediment resulting from anthropogenic land use change.

\section{AFFILIATIONS}

'School of Environment Education and Development, The University of Manchester, UK

${ }^{2} \mathrm{School}$ of Geography and the Environment, University of Oxford, UK

\section{CONTACT}

Abi Stone: abi.stone@manchester.ac.uk REFERENCES

Cook PG et al. (1994) Water Resour Res 30: 1709-1719 Edmunds WM, Tyler SW (2002) Hydrogeol J 10: 216-228 Gates JB et al. (2008) Holocene 18: 1045-1054 Gehrels JC (1998) Hydrolog Sci J 43: 579-594 Ginn TR, Murphy EM (1997) Water Resour Res 33: 2065-2079

Ma J, Edmunds WM (2006) Hydrogeol J 14: 1231-1243

Ma J et al. (2009) Palaeogr Palaeocl 276: 38-46 Phillips FM (1994) Soil Sci Soc Am 58: 15-24 Scanlon BR (1991) J Hydrol 128: 137-156 Scanlon BR et al. (2010) Hydrogeol J 18: $959-972$ Sheppard PR et al. (2004) Clim Dyn 23: 869-881 Stone AEC, Edmunds WM (2016) Earth-Sci Rev 157 121-144

Thompson LG et al. (1997) Science 276: 1821-1825 Tyler SW et al. (1996) Water Resour Res 32: 1481-1499 Zhang P, Crowley TJ (1989) J Clim 2: 833-849 